\title{
Pengaruh Karbon Aktif Komposit Hibrida pada Absorpsi Air Permukaan
}

\author{
Daniel Lihoudo Williams P1), I.D.G Ary Subagia ${ }^{1)^{*}}$, A.A.I.A Sri Komaladewi1) \\ 1)Program Studi Teknik Mesin, Fakultas Teknik, Universitas Udayana, Bukit Jimbaran, Badung, Bali \\ Naskah diterima 29/01/2019; direvisi 10/04/2019; disetujui 27/04/2019 \\ doi: https://doi.org/10.24843/JEM.2019.v12.i01.p09
}

\begin{abstract}
Abstrak
Penelitian ini bertujuan mengetahui unjuk kerja komposit hibrida dalam proses adsorpsi air permukaan. Komposit hibrida merupakan bahan yang terdiri dari morninga olifera (MO) dan activated carbon (AC) sebagai fillers, dan tepung lengket sebagai polimer yang diproduksi menggunakan cetakan penekanan panas (hot-press mold) pada temperatur $200^{\circ} \mathrm{C}$. Komposisi filler dan polimer didasarkan pada rasio fraksi berat yaitu $40 \%$ filler dan $60 \%$ polimer. Kualitas absorpsi komposit hibrida dilakukan melalui proses perendaman dan turbidity test. Hasil pengujian perendaman benda kerja selama dua minggu adalah waktu paling optimal dari kenaikan massa komposit hibrida yang direndam pada air permukaan untuk masing-masing variasi hibrida. Peningkatan jumlah prosentase AC pada benda uji meningkatkan kekeruhan air karena adanya pelepasan unsur C pada air sesuai dengan test turbiditasnya. Kemudian, kandungan coliform dan E-coli pada air permukaan menurun disebabkan oleh meningkatnya prosentase MO pada benda uji. Dari hasil tersebut, disimpulkan bahwa hibridisasi filler MO dan AC memberikan dampak positif terhadap kualitas air permukaan.
\end{abstract}

Kata kunci: Absorpsi, Komposit hibrida, Karbon aktif, Moringa oleifera, Air permukaan

\begin{abstract}
The purpose of this research is see the work method of the "Hybrid Composite" on the absorption process on the water surface. These "Hybrid Composite" was the material that contains Moringa Oleifera (MO) and Activated Carbon (AC) as the fillers, and sticky wood flour as the polimer that produced by using the Hot-Press molder on the temperature of $200^{\circ} \mathrm{C}$. the composition of the polimer and the filler itself is based on the weight fraction as $40 \%$ Filler and $60 \%$ Polymer. The quality of the absorption of the "Hybrid" is tested using Turbidity and the submersion test. The results after being kept for 2 week and the consideration of the optimal time. The increasing of AC percentages on the specimens test increases turbidity result of water due to the release of element $\mathrm{C}$ in water according to the turbidity test. Then, the Coliform and E.Coli content in surface water decreased due to the increase in $\mathrm{MO}$ percentage of the specimen. From these results, it was concluded that $\mathrm{MO}$ and $\mathrm{AC}$ filler hybridization has a positive impact on the quality of surface water.
\end{abstract}

Keywords: Absorption, Hybrid composite, Activated carbon, Moringa oleifera, Surface water

\section{Pendahuluan}

Undang-Undang nomor 7 Tahun 2004 mengenai Sumber Daya Air pada pasal 5 dan Keputusan Menteri Kesehatan Republik Indonesia No.907/Menkes /SK/VII/2002 air agar dapat dikonsumsi Peningkatan peradaban manusia telah memberikan dampak pada kualitas air [1]. Sekarang ini kualitas air menurun drastis yang disebabkan oleh adanya pencemaran baik dari sumber organik maupun anorganik [2, 3]. Air yang layak konsumsi harus memenuhi syarat kesehatan dimana tidak boleh menimbulkan gangguan kesehatan dan juga perlu ditetapkan persyaratan kesehatan kualitas air minum. Warna, bau dan rasa merupakan aspek yang dinilai secara kasatmata dalam menilai air bersih atau tidak [4, 5]. Saat ini, ketersediaan air yang layak konsumsi di Indonesia baru mencapai 49\% pada tahun 2007 .

Kenyataan tersebut telah mendorong berbagai upaya manusia untuk memperbaiki kualitas air. Bentuk-bentuk inovasi yang telah dilakukan adalah dengan menciptakan alat-alat penyaring baik penyaring tradisional maupun membran [6-9]. Beberapa bentuk penyaringan air yang telah dikembangkan secara tradisional adalah penjernihan air dengan saringan pasir [9], kemudian perbaikan kualitas air permukaan dengan metode membran dilakukan dengan metode (RO) reverse osmosis menggunakan bahan polimer permeator dengan jenis struktur molekul Poliamida [10,11]

Bertitik tolak dari hasil perbaikan kualitas air dengan metode tersebut diatas, diperoleh hasil yang belum optimal karena belum secara keseluruhan secara bersamaan polutan pada air dapat dihilangkan. Selanjutnya melihat kemampuan dari bahan moringa oleifera (MO) $[12,13]$ dan activated carbon (CA) [14, 15] menjadi mungkin untuk dikembangkan bahan penyaring air permukaan [16-18]. Pada kesempatan ini kedua bahan tersebut di hibridisasi dalam pengikat tepung lengket sebagai komposit hibrida. Inovasi ini belum banyak dilakukan oleh peneliti lain sehingga sangat memungkinkan untuk dipelajari baik sifat fisik dan mekanik.

Penelitian ini dilaksanakan dengan melakukan hibridisasi Moringan Olifera (MO) dan Activied carbon (AC) pada pengikat serbuk lengket. Hibridisasi [19] yang dilakukan didasarkan pada rasio perbandingan berat (weight fraction) yaitu $40 \%$ gabungan antar MO dan $A C$, dan $60 \%$ serbuk tepung lengket. Kandungan antara $\mathrm{MO}$ dan $\mathrm{AC}$ adalah divariasikan yaitu $10 \%$, $20 \%, 30 \%$ dan $40 \%$ AC terhadap MO. Proses absorpsi dilakukan untuk mengetahui sifat terserap dan terikat dari polutan pada benda uji, yang dilaksanakan

${ }^{*}$ Korespondensi:

E-mail: arsubmt@me.unud.ac.id 
dengan tahapan perendaman. Kemudian pengujian turbidity dilakukan untuk mengetahui dampak komposit hibrida terhadap kekeruhan air. Hasil pengujian dianalisa dengan SEM untuk mengetahui polutan terabsorp dan teradsorpsi pada komposit hibrida.

\section{Metode Penelitian}

\subsection{Bahan komposit hibrida}

Komposit hibrida telah dibuat pada penelitian ini untuk bahan perbaikan kualitas air permukaan tercemar. Komposit hibrida dibuat dengan komposisi $40 \%$ sebagai filler dan $60 \%$ sebagai pengikat. Bahan filler yang digunakan adalah $\mathrm{MO}$ dan AC. MO adalah bahan organik yang diperoleh dari tumbuhan kelor. MO memiliki sifat yang baik sebagai penyerap polutan air karena memiliki zat aktif yaitu 4-alfa4rhamnosyloxy-benzil-isothiocyanate [9]. Gugus ikatan dari moringa ditunjukkan seperti Gambar 1.<smiles></smiles>

Gambar 1. Rantai ikatan Moringa Oleifera

Kemudian AC adalah bahan organik yang banyak dihasilkan dari arang kayu dan batok kelapa. AC dibuat melalui proses pirolisis pada temperatur diatas $700^{\circ} \mathrm{C}$, sehingga dikenal dengan karbon aktif. AC memiliki manfaat untuk pemurnian cairan dan gas, pemisahan campuran dan pengemban katalis logam. Selanjutnya, tepung lengket adalah bahan yang dibuat sedemikian rupa dari serbuk kayu dengan mencampurkan perekat untuk mengikat. Bahan-bahan yang digunakan pada komposit hibrida ini adalah berbentuk serbuk dengan ukuran butir 100mesh uniform seperti ditunjukan pada Gambar 2.
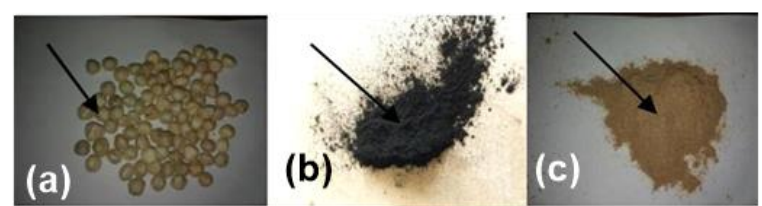

Gambar 2. Bahan Komposit Hibrida. a) Biji kelor, b) Karbon aktif dan c) Tepung lengket

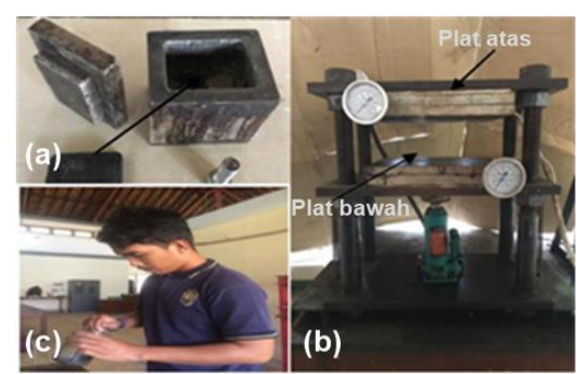

Gambar 3 Proses pengerjaan benda uji a).Cetakan, b)mesin press, c proses pengisian cetakan.

Cetakan dengan penekan panas (Hot-press mold) telah digunakan untuk memproduksi komposit hibrida untuk setiap variasi seperti tunjukkan pada Gambar 3a. Panas penekan cetakan dibedakan menjadi dua yaitu temperatur $200^{\circ} \mathrm{C}$ untuk plat $\mathrm{A}$ dan $250^{\circ} \mathrm{C}$ untuk plat B (lihat Gambar 3b). Tahapan pencetakan benda kerja dimulai dari proses pencampuran antara $\mathrm{MO}, \mathrm{AC}$ dan tepung lengket. Kemudian dilanjutkan dengan pemasukan campuran dalam cetakan (lihat Gambar 3c). Setelah itu proses pengepresan ditunjukan seperti pada gambar $3 \mathrm{~b}$. pada tahap pengepresan dilakukan dalam waktu kurang lebih 2 jam dengan beban konstan 2000 Psi. Proses akhir adalah proses pengeluaran benda kerja dari cetakan.

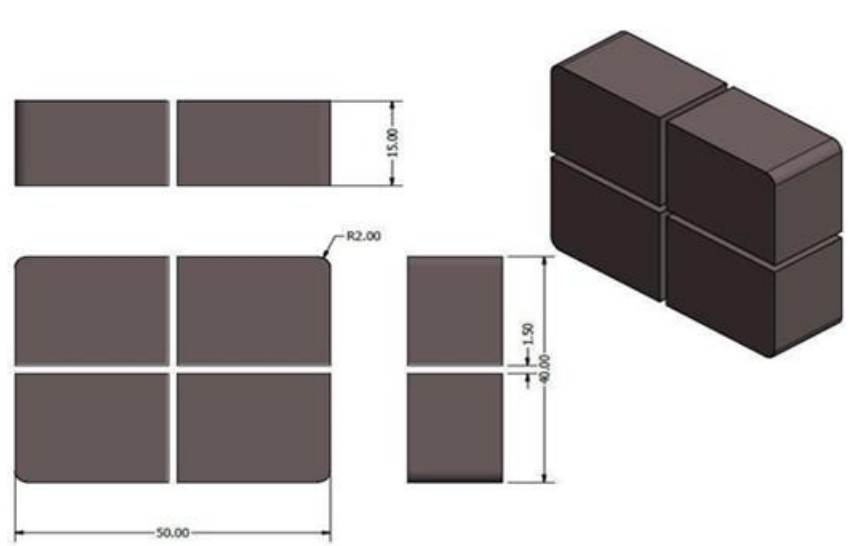

Gambar 4. Geometri benda uji Komposit Hibrida

Gambar 4 menunjukan geometri benda kerja yang disiapkan untuk pengujian perendaman dalam air permukaan terkontaminasi.
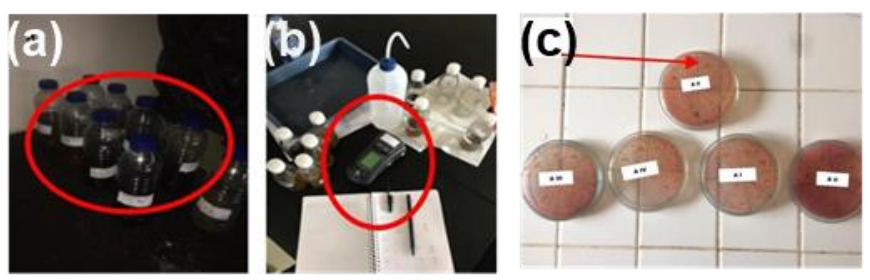

Gambar 5. Pengujian Komposit Hibrida. a) Uji penyerapan air, b) Uji Turbidity, c) Uji Mikrobiologi

\subsection{Proses Pengujian Komposit Hibrida}

Gambar 5a,b, dan c berturutan menunjukkan pengujian kualitas air dengan absorpsi komposit hibrida mengandung bahan MO dan AC. Gambar 5a menunjukkan tahapan pengujian absorpsi komposit hibrida. Terdapat di kondisi air yaitu air bersih (aquades) dan air permukaan (terkontaminasi). Pada tahap absorpsi benda kerja direndam pada kedua tipe air selama 2 minggu. Pengujian ini dilakukan untuk mengetahui sifat absorpsi dari MO dan AC terhadap polutan air [20]. Perubahan kandungan dari benda uji sebelum dan sesudah perendaman adalah dihasilkan perubahan mass yang dihitung dengan persamaan:

$$
m u=\left(\left(m_{1}-m_{0}\right) / m_{0}\right) \times 100 \%
$$

Dimana :

$$
\begin{aligned}
& m_{u}=\text { Pertambahan massa benda uji }(\%) \\
& m_{1}=\text { massa akhir }(\mathrm{gr}) \mathrm{m} 0=\text { massa awal }(\mathrm{gr})
\end{aligned}
$$

Turbidity test adalah pengujian yang dilakukan untuk mengamati tingkat kekeruhan air yang dihasilkan setelah perendaman yang prosesnya ditunjukkan pada Gambar 5b. uji Turbidity dipakai untuk menganalisa pengaruh komposisi karbon aktif terhadap kekeruhan air. Uji Mikrobiologi menunjukkan 
pengaruh karbon aktif dan biji kelor terhadap pertumbuhan Coliform dan E.Coli pada air.

\section{Hasil dan Pembahasan}

3.1. Water Absorption Komposit Hibrida

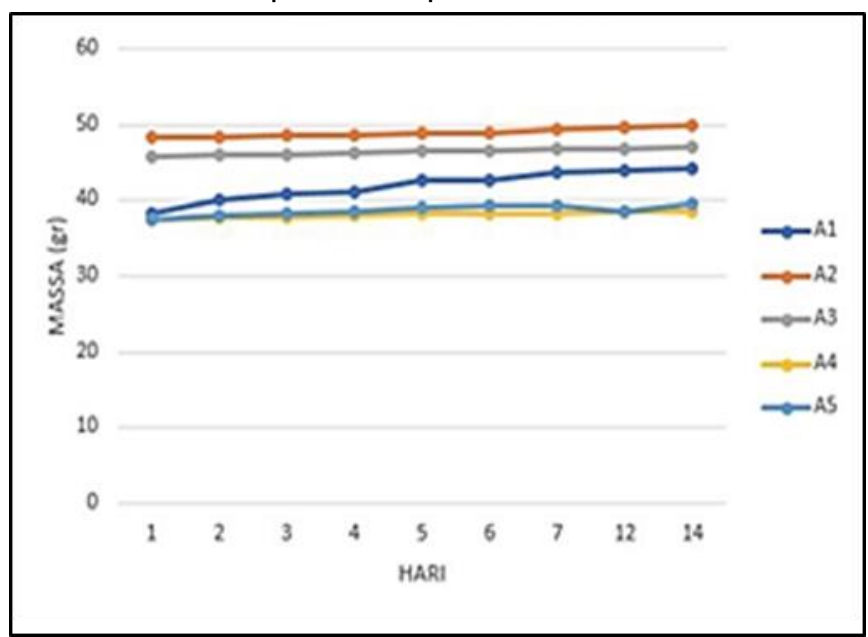

Gambar 6. Kondisi kenaikan massa komposit hibrida

Gambar 6 menunjukkan kondisi kenaikan massa dari komposit hibrida untuk setiap variasi selama 14 hari perendaman di air permukaan terkontaminasi. Dari hasil tersebut dapat diamati bahwa selama 14 hari perendaman telah merubah massa komposit hibrida masing-masing yaitu rata-rata 9,3\% dari kondisi kering. Komposit hibrida (A1 dan A5) masingmasing dengan komposisi seperti ditunjukkan pada Tabel 1, memiliki kenaikan massa setelah perendaman yang paling rendah yaitu sebesar $1,5 \%$. Kondisi ini dikarenakan AV (40\% MO) memiliki poripori lebih kecil dibandingkan karbon aktif. Sebaliknya semua komposisi lihat Tabel 1 memiliki nilai pertambahan massa setelah perendaman tertinggi yaitu 49,9 gram. Kondisi ini dikarenakan oleh morfologi karbon aktif yang memiliki pori-pori yang lebih besar dibandingkan dengan $\mathrm{MO}$ [21].

Penambahan massa dipengaruhi oleh variasi komposisi seperti Tabel 2 dan Tabel 3, setiap hari mengalami kenaikan hingga konstan terjadi pada hari ke 6 dan seterusnya.

Tabel 1 berat benda uji setelah perendaman

\begin{tabular}{cccccc}
\hline Material & \multicolumn{5}{c}{ Hari/gram } \\
\cline { 2 - 6 } & 1 & 4 & 7 & 12 & 14 \\
\hline A1 & 38.38 & 41.23 & 43.67 & 43.93 & 44.18 \\
A2 & 48.31 & 48.57 & 49.35 & 49.72 & 49.90 \\
A3 & 45.75 & 46.28 & 46.77 & 46.81 & 46.98 \\
A4 & 37.42 & 38.01 & 38.35 & 38.55 & 38.60 \\
A5 & 37.5 & 38.65 & 39.37 & 38.60 & 39.62 \\
\hline
\end{tabular}

\subsection{Turbidity Komposit Hibrida}

Kekeruhan (turbidity) merupakan kondisi air yang paling mudah diamati, dan hal ini dapat memberikan nilai negative dari kualitas air. Kekeruhan disebabkan adanya kehadiran zat-zat lainnya. Kehadiran zat-zat yang dimaksud terlarut dalam zat cair dan membuatnya seperti berkabut atau tidak jernih.

Gambar 7 menunjukkan sifat kekeruhan air permukaan setelah perendaman komposit hibrida untuk masing - masing variasi. Gambar 7 membandingkan arah vertikal adalah NTU dan arah horizontal adalah benda uji, dan hasil pengamatan dari grafik diatas bahwa banyaknya kandungan AC dan MO mempengaruhi kekeruhan air permukaan. Hasil pengujian dapat disimpulkan bahwa semakin banyak kandungan AC (Karbon aktif) maka lama-kelamaan air akan menjadi lebih keruh dikarenakan CA hancur setelah proses perendaman selama 14 hari, begitu juga sebaliknya apabila kandungan karbon sedikit maka kekeruhannya akan berkurang dan lebih rendah dibanding dengan air tanpa proses perendaman komposit hibrida.

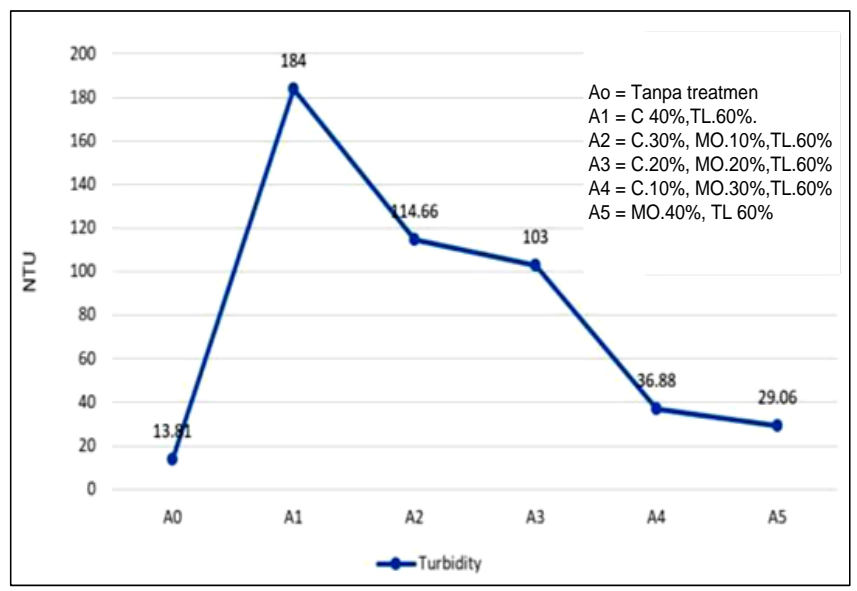

Gambar 7. Grafik hasil pengujian Turbidity

\subsection{Mikrobiologi Komposit Hibrida}

Mikrobiologi atau mikroorganisme merupakan makhluk hidup yang memiliki ukuran yang sangatlah kecil. Pengujian mikrobiologi ini ditujukan untuk airpermukaan yang mengalami perendaman komposit hibrida. Dimana, air permukaan yang terkontaminasi mikroorganisme yang berbahaya bagi kesehatan makhluk hidup. Uji Mikrobiologi ini menunjukkan kandungan Coliform dan E.Coli pada air permukaan sebelum dan sesudah perendaman komposit hibrida selama 2 minggu.

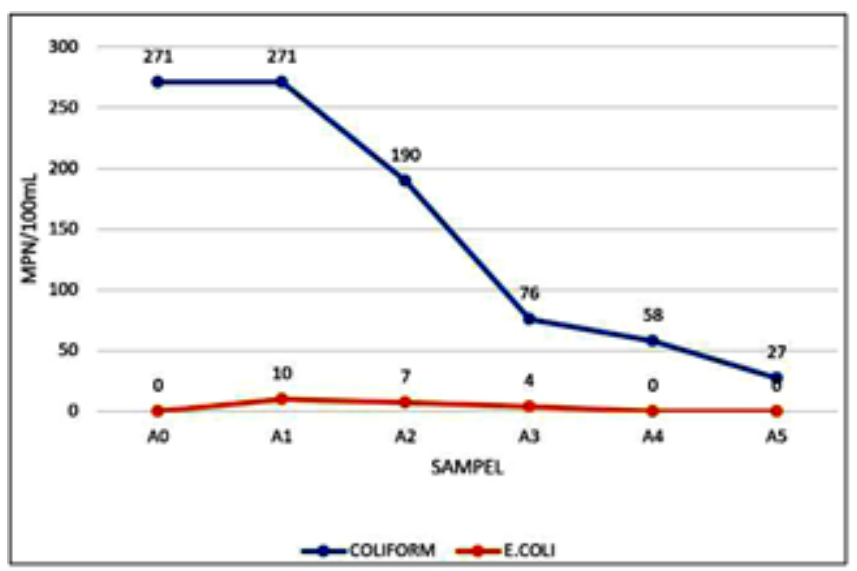

Gambar 8. Grafik hasil pengujian mikrobiologi Coliform dan E.Coli

Gambar 8 ditunjukkan hubungan kandungan Coliform dan E.Coli pada air pada material dengan variasi kandungan $\mathrm{MO}$ dan $\mathrm{AC}$. Teramati bahwa $\mathrm{MO}$ dan AC berpengaruh positf terhadap kandungan Coliform dan E.Coli dalam satuan MPN/100ml air permukaan. Demikian, dapat disimpulkan bahwa 
semakin banyak kandungan MO akan semakin rendah Coliform dan E.Coli yang terkandung pada air tersebut.

\subsection{Analisa Photograph Komposit Hibrida}

SEM (Scanning Electron Microscopy) adalah alat yang digunakan untuk melihat permukaan dari sebuah benda uji atau komposit hibrida. Pada (Gambar 9) dapat dilihat perbedaan pada benda uji antara sebelum dan sesudah proses perendaman benda uji pada air permukaan terkontaminasi. EDS (Energy Dispersive Spectroscopy) dimana digunakan untuk mengetahui kandungan unsur pada sebuah benda uji dititik yang ditentukan.
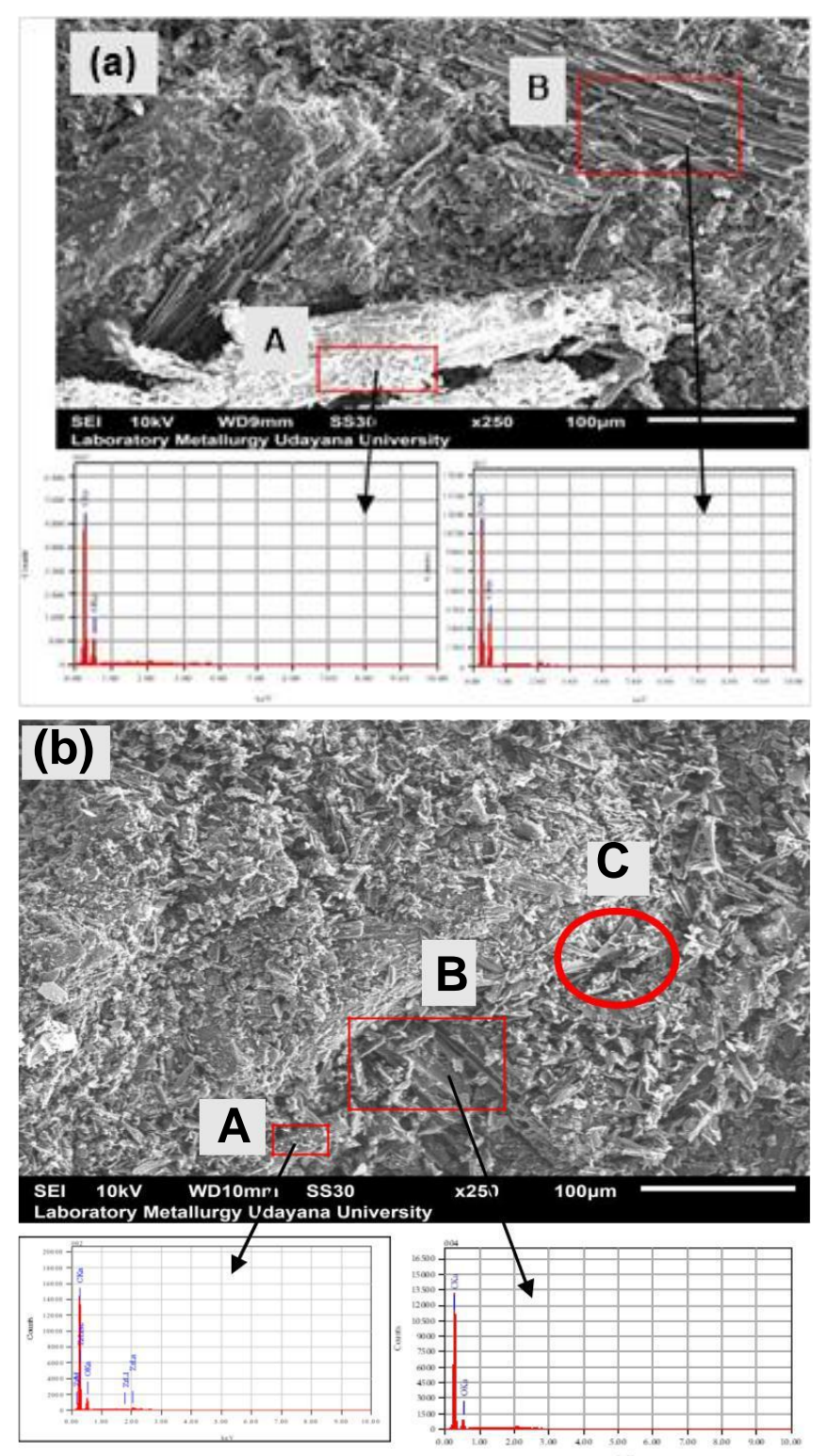

Gambar 9. Analisa pengamatan SEM dan EDS material a). Sebelum perendaman komposit hibrida, b). Sesudah perendaman komposit hibrida (A : Tepung Lengket, B : Karbon aktif dan C: Polutan)

Hasil pengamatan diperoleh bahwa polutan terabsorpsi pada material komposit hibrida untuk semua komposisi MO dan CA. Kenyataan tersebut ditunjukkan pada Gambar 9a dan b. Terlihat pada penampakan permukaan. Huruf bear A, B dan C pada kotak dan lingkaran di gambar SEM menunjukkan

daerah teramati EDS untuk menentukan nilai absorpsi polutan pada air setelah terserap oleh komposit hibrida. Nilai absorpsi polutan pada komposit hibrida dari analisa EDS dengan nilai masing masing ditunjukkan pada Tabel 2 dan 3.

Tabel 2. Nilai pengamatan EDS area A sebelum dan setelah perendaman.

\begin{tabular}{c|cccc}
\hline \multirow{2}{*}{ Elemen } & \multicolumn{2}{|c}{ Sebelum } & \multicolumn{2}{c}{ Sesudah } \\
& $\mathrm{KeV}$ & Mass\% & $\mathrm{KeV}$ & Mass\% \\
\hline $\mathrm{C}$ & 0.277 & 63.12 & 0.277 & 72.80 \\
$\mathrm{O}$ & 0.525 & 36.88 & 0.525 & 27.20 \\
Total & & 100 & & 100 \\
\hline
\end{tabular}

Tabel 3. Nilai pengamatan EDS area B sebelum dan setelah perendaman.

\begin{tabular}{ccccc}
\hline \multirow{2}{*}{ Elemen } & \multicolumn{2}{c}{ Sebelum } & \multicolumn{2}{c}{ Sesudah } \\
& $\mathrm{KeV}$ & Mass\% & $\mathrm{KeV}$ & Mass\% \\
\hline $\mathrm{C}$ & 0.277 & 79.38 & 0.277 & 84.81 \\
$\mathrm{O}$ & 0.525 & 16.47 & 0.525 & 15.19 \\
$\mathrm{Zr}$ & 2.042 & 4.15 & - & - \\
Total & & 100 & & 100 \\
\hline
\end{tabular}

\section{Simpulan}

Komposit hibrida telah dibuat pada penelitian ini, yang diujikan dengan perendaman pada air untu memperbaiki kualitas air tercemar. Komposit hibrida dibuat dengan komposisi $40 \%$ sebagai filler dan $60 \%$ sebagai pengikat. Bahan filler yang digunakan adalah MO dan AC. Hasil pengujian disimpulkan bahwa;

1. Pembuatan komposit hibrida menjadi salah satu alternative dalam perbaikan kualitas air dan mengurangi penggunaan zat kimia pada umumnya yang digunakan untuk perbaikan kualitas air.

2. Penggunaan karbon aktif dan MO pada komposit hibrida mempengaruhi tingkat kejernihan (turbidity) dan jumlah Coliform serta E.Coli pada air permukaan.

3. Jumlah Coliform dan E.Coli dipengaruhi oleh banyaknya komposisi dari biji kelor (MO) pada komposit hibrida itu sendiri.

\section{Daftar Pustaka}

[5] I. Iman, T. Nuryastuti, danL. Herawati, "Analisis laik sehat dan kualitas mikrobiologis 
air minum isi ulang di kecamatan ligung, majalengka," Berita Kedokteran Masyarakat, 32, 179-182, 2016.

[6] N. Arahman., "Basic concepts of porous membrane process method with non-solvent induced phase separation - determination of cloud point and three-phase diagram," Jurnal Rekayasa Kimia dan Lingkungan, 9, No. 2, 68 - 73, 2012.

[7] M. Padaki, R. Surya Murali, M.S. Abdullah, N. Misdan, A. Moslehyani, M.A. Kassim, N. Hilal, danA.F. Ismail, "Membrane technology enhancement in oil-water separation. A review," Desalination, 357, 197-207, 2015.

[8] S. Khoonsap, N. Supanchaiyamat, A.J. Hunt, S. Klinsrisuk, danS. Amnuaypanich, "Improving water selectivity of poly (vinyl alcohol) (pva) - fumed silica (fs) nanocomposite membranes by grafting of poly (2-hydroxyethyl methacrylate) (phema) on fumed silica particles," Chemical Engineering Science, 122, 373-383, 2015.

[9] Z. Wang, J. Ma, C.Y. Tang, K. Kimura, Q. Wang, danX. Han, "Membrane cleaning in membrane bioreactors: A review," Journal of Membrane Science, 468, 276-307, 2014.

[10] Jun Yindan B. Deng., "Polymer-matrix nanocomposite membranes for water treatment," Journal of Membrane Science, 479, 256-275, 2015.

[11] S.P. Rozitawatidan L. Noerochim., "Karakterisasi membran polimer dengan adsorben inorganik lithium mangan spinel untuk ekstraksi lithium dari lumpur sidoarjo," JURNAL TEKNIK POMITS, 3, No. 2, 2014.

[12] S.N. Sinha, "Phytochemical analysis and antibacterial potential of moringa oleifera lam," International Journal of Science Innovations and Discoveries (IJSID), 2 401-407, 2012.

[13] Y.I. Rani, "Penggunaan serbuk biji kelor (moringa oleifera) sebagai koagulan dan flokulan dalam perbaikan kualitas air limbah dan air tanah," Tesis]. Universitas Islam Negeri Jakarta, 2010.

[14] I.A. Tan, A.L. Ahmad, danB.H. Hameed, "Preparation of activated carbon from coconut husk: Optimization study on removal of 2,4,6trichlorophenol using response surface methodology," J Hazard Mater, 153, 709-17, 2008.

[15] A.M.-K.a.R. Ansari., "Activated charcoal: Preparation, characterization and applications : A review article," International Journal of ChemTech Research (IJCRGG), 1, No.4, 859-864, 2009.

[16] Jafari, Mahvi, Godini, Rezaee, danHosseini., "Process optimization for fluoride removal from water by moringa oleifera seed extract," Research report Fluoride 47, 152-160., 2014.

[17] L.-L. Hwang, M.-Y. Wey, danJ.-C. Chen, "Effects of membrane compositions and operating conditions on the filtration and backwashing performance of the activated carbon polymer composite membranes," Desalination, 352, 181-189, 2014.

[18] S. Das, "Characterization of activated carbon of coconut shell, rice husk and karanja oil cake," Bachelor, Chemical Engineering, National Institute of Technology, Rourkela, 2014.

[19] C. Stoquart, P. Servais, P.R. Bérubé, danB. Barbeau, "Hybrid membrane processes using activated carbon treatment for drinking water: A review," Journal of Membrane Science, 411412, 1-12, 2012.

[20] Tambak Manurung, Yusriani Sapta Dewi, danB. J.Lekatompessy, "Efektivitas biji kelor (moringa oleifera) pada pengolahan air sumur tercemar limbah domestik," Jurnal IImiah Fakultas Teknik LIMIT'S, 8 Nomor 137 - 46, 2012.

[21] Syahru Ramadhani, Alexander Tunggul Sutanhaji, danD.B.R. Widiatmono, "Perbandingan efektivitas tepung biji kelor (moringa oleifera lamk), poly aluminium chloride (pac), dan tawas sebagai koagulan untuk air jernih," Jurnal Keteknikan Pertanian Tropis dan Biosistem, Vol. 1 No. 3, 186-193, 2013. 